\title{
Effect of Incorporating a Trace Amount of Fluorocarbon into Poly(N-isopropylacrylamide) on Its Association in Water
}

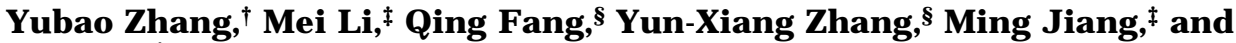 Chi Wu,t,ll}

Department of Chemistry, The Chinese University of Hong Kong, Shatin, Hong Kong, Institute of Macromolecular Science, Fudan University, Shanghai 200433, China, Shanghai Institute of Organic Chemistry, Academia Sinica, Shanghai 200032, China, and The Open Laboratory for Bond Selective Chemistry, Department of Chemical Physics, University of Science \& Technology of China, Hefei, Anhui, China

Received September 25, 1997; Revised Manuscript Received J anuary 22, 1998

\begin{abstract}
A combination of laser light scattering (LLS), viscometry, and fluorescence spectroscopy was used to study the association of a series of fluorocarbon-modified poly( $\mathrm{N}$-isopropylacrylamide) (PNIPAM) copol ymers in aqueous solution. The interchain association increases as both the fluorocarbon content and polymer concentration increase, evidenced by the changes of the apparent molar mass, intrinsic viscosity, Huggins constant, and fluorescence excimer-to-monomer intensity ratio. The LLS results are well-represented by the open association model. Our results al so reveal ed that the intrachain association starts when each polymer chain, on average, has more than two fluorocarbon monomers.
\end{abstract}

\section{Introduction}

The hydrophobic associations in aqueous media have long been recognized in the synthesis of small organic molecules or biopolymers. ${ }^{1-3}$ Only recently, some attention has been paid to the hydrophobic associations and solution rheology of water-soluble synthetic polymers with a small number of hydrophobic side groups on their chain backbones. ${ }^{4-16}$ Various kinds of hydrophobically modified water-soluble polymers, such as lauryl acrylate or -methacrylate, $\mathrm{N}$-alkylacrylamides, ${ }^{10-13}$ and n-alkyl-grafted cellulose ethers, 14,15 were synthesized and studied in terms of their rheological properties. Recently, Zhang et al. ${ }^{16}$ synthesized a new kind of water-soluble polymer with a small number of fluorocarbon moieties. This kind of novel copolymer can effectively enhance the solution viscosity more than the corresponding hydrocarbon-modified copolymers because fluorocarbon monomers have a much more pronounced hydrophobic character. Experimentally, it is easier to detect the small number of fluorocarbon comonomers in a copolymer chain by either NMR or el emental analysis, so that we are able to correlate the association and rheology properties of these copolymers to their chemical structures.

Poly(N-isopropylacrylamide) (PNIPAM) as a thermal sensitive water-soluble polymer has been extensively studied. ${ }^{17}$ It is well-known that a PNIPAM hydrogel can undergo a reversible volume change in response to chemical and physical stimuli, such as temperature, solvent composition, $\mathrm{pH}$, and ions. The hydrocarbon modification of PNIPAM was reported by Rinsdorf $\mathrm{f}^{18}$ and Schild. ${ }^{19}$ The association of a hydrocarbon-modified PNIPAM and the alternation of its low critical solution temperature (LCST) were investigated by Winnik. ${ }^{20}$ The

\footnotetext{
* To whom correspondence should be addressed at the Chinese University of Hong Kong.

† The Chinese University of Hong Kong.

‡ Fudan University.

$\S$ Academia Sinica.

" University of Science \& Technology of China.
}

fluorescence study revealed the existence of multichain micelles in solution. Recently, Zhang et al. ${ }^{21}$ synthesized a series of the fluorocarbon-modified PNIPAM samples and found that when the fluorocarbon content is in the range $0.007-0.7 \mathrm{~mol} \%$, the copolymer solutions can display a shear thickening behavior, contrary to a previously observed shear thinning behavior displayed by the hydrocarbon-modified PNIPAM or polyacrylamide.

Despite a wide range of applications of hydrophobically modified water-soluble polymers, a complete understanding of the hydrophobic interaction among the polymer chains is still missing. Recently, various modern experimental methods, such as fluorescence spectroscopy, 22-24 nuclear magnetic resonance (NMR), ${ }^{25,27}$ and laser light scattering (LLS), ${ }^{28,29}$ were used to study the hydrophobic associati on of water-soluble polymers, mainly focusing on the characterization of the hydrophobic microdomains and the correlation between the hydrophobic microstructures and macroscopic properties. Each method has a limited detection range, so that a combination of several complementary methods is often required. This is why we intend to use a combination of laser light scattering, fluorescence, and viscometry to study a series of fluorocarbon-modified PNIPAM samples, so that we can find how the fluorocarbon content affects the hydrophobic association at different structural levels and relate their chemical structures to the hydrophobic microstructures as well as the rheological properties.

\section{Experimental Section}

Sample Preparation. N-I sopropylacrylamide purchased from Eastman Kodak was recrystallized twice in a hexane/ benzene $(v / v=65 / 35)$ mixture. The fluorine-containing surfactant potassium perfluorooctanecarboxylate (FC-143), 2-(Nethyl (perfluorooctylsulfo)amido)ethyl acrylate monomer ( $\mathrm{Fx}$ $13)$, and methacrylate monomer ( $F x-14)$ (courtesy of $3 M$ company) were recrystallized in methanol. All the solvents and salts used were of reagent grade. The chemical structures of FC-143, Fx-13, and Fx-14 are as follows: 


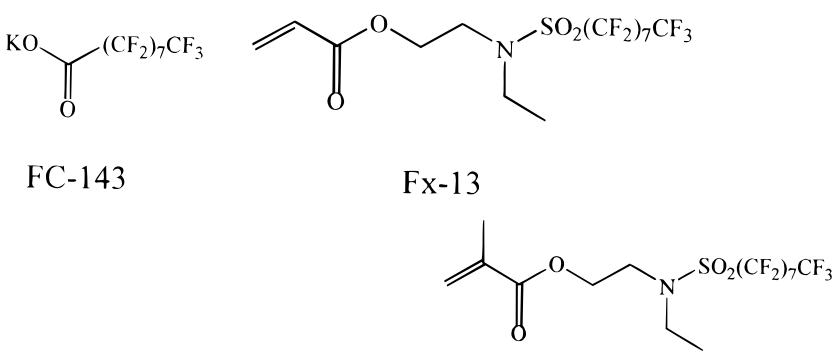

Fx-14

The copolymerization of acrylamide and $\mathrm{Fx}-13$ or $\mathrm{Fx}-14$ was detailed before. ${ }^{21}$ Into a $50-\mathrm{mL}$ round-bottom flask were added $2.26 \mathrm{~g}$ of NIPAM (20 mmol), a desired amount of the fluorocarbon monomer, and $0.1 \mathrm{mmol}$ of AIBN. The mixture was purged with nitrogen for 15 min before initiating the reaction at $60.0 \pm 0.5^{\circ} \mathrm{C}$ for $24 \mathrm{~h}$. The polymerization was stopped by cooling the mixture down to room temperature. The copolymer was precipitated in $500 \mathrm{~mL}$ of ethyl ether. The precipitate was redissolved in $20 \mathrm{~mL}$ of acetone and reprecipitated in 500 $\mathrm{mL}$ of ethyl ether. The final precipitate was dried in a vacuum at $40{ }^{\circ} \mathrm{C}$ for $24 \mathrm{~h}$.

Anion Chromatography. Anion chromatography is based on the anion-exchange process occurring between a mobile phase (eluent and anion) and a stationary phase (a cross-linked polystyrene bead modified with quaternary ammonium groups). Separation of anions (fluorocarbon-modified polymers were burned to produce $\mathrm{F}^{-}$) is based on the affinity difference between $\mathrm{F}^{-}$and quaternary ammonium. The concentration of $\mathrm{F}^{-}$is detected by conductivity. With a direct injection of a $50-\mathrm{mL}$ sample, the detection limit is $\sim 10 \mathrm{ppb}$. Therefore, the concentration of $\mathrm{F}^{-}$can be precisely determined with an error no more than $\pm 3 \%$ in our experiments. The fluorocarbon content determined by anion chromatography (Dionex 2110I) was listed in Table 1.

Laser Light Scattering. The LLS instrumentation was detailed before. ${ }^{29}$ The refractive index increment $(\mathrm{dn} / \mathrm{dC})$ was determined by a novel and precise differential refractometer.$^{30}$ All the measurements were done at $25.0 \pm 0.1{ }^{\circ} \mathrm{C}$. In static LLS, the angular dependences of the excess absolute timeaveraged scattered intensity, known as the excess Rayleigh ratio $R_{v v}(q)$, of dilute copolymer solutions were measured. $R_{v v}(q)$ is related to the weight average molar mass $M_{w}$, the second virial coefficient $A_{2}$, and the z-average root-meansquare radius of gyration $\left\langle R_{g}^{2}\right\rangle_{z}^{1 / 2}$ (or simply as $\left\langle R_{g}\right\rangle$ ) by ${ }^{31}$

$$
\frac{K C}{R_{v v}(q)} \cong \frac{1}{M_{w}}\left(1+\frac{1}{3}\left\langle R_{g}^{2}\right\rangle q^{2}\right)+2 A_{2} C
$$

where $\mathrm{K}=4 \pi^{2} \mathrm{n}^{2}(\mathrm{dn} / \mathrm{dC})^{2} /\left(\mathrm{N}_{\mathrm{A}} \lambda_{0}^{4}\right)$ and $\mathrm{q}=\left(4 \pi \mathrm{n} / \lambda_{0}\right) \sin (\theta / 2)$ with $\mathrm{N}_{\mathrm{A}}, \mathrm{n}, \lambda_{0}$, and $\theta$ being Avogadro's constant, the solvent refractive index, the light wavelength in a vacuum, and the scattering angle, respectively.

In dynamic LLS, the Laplace inversion of the measured intensity-intensity time correlation function $\mathrm{G}^{(2)}(\mathrm{t}, \mathrm{q})$ led to the line-width distribution $\mathrm{G}(\Gamma) \mathrm{r}^{32-34}$ If the relaxation is diffusive, $\Gamma$ is related to the translational diffusion coefficient $D$ by $\left[\Gamma / q^{2}\right]_{C \rightarrow 0, \theta \rightarrow 0}=D \cdot{ }^{35,36}$ Further, $D$ is related to the hydrodynamic radius $\left(R_{h}\right)$ by the Stokes-Einstein equation, $R_{h}=k_{B} T /$ $6 \pi \eta \mathrm{D}$, where $\mathrm{K}_{\mathrm{B}}, \eta$, and $\mathrm{T}$ are the Boltzmann constant, the solvent viscosity, and the absolute temperature, respectively. The concentration of the stock solutions was in the range (25) $\times 10^{-3} \mathrm{~g} / \mathrm{mL}$. The deionized water used had an electric conductivity of $18.3 \mathrm{M} \Omega \mathrm{cm}$. The solutions were clarified with a $0.2-\mu \mathrm{m}$ Anotop Whatman filter. The copol ymers were soluble in THF, so that the characteristics of individual copolymer chains were studied. All the THF solutions were clarified with a $0.2-\mu \mathrm{m}$ PTFE Whatman filter.

Steady-State Fluorescence Measurements. Steadystate fluorescence spectra were recorded by using a Hitachi F-4500 fluorescence spectrophotometer with a right angle geometry $\left(90^{\circ}\right.$ collecting optics). The slit widths for excitation and emission are 5 and $2.5 \mathrm{~nm}$, respectively. For emission spectra, $\lambda_{\mathrm{ex}}=333 \mathrm{~nm}$, while for excitation spectra, $\lambda_{\mathrm{em}}=340$ $\mathrm{nm}$. All the spectra were recorded on air-saturated samples. The association of hydrocarbon-modified water-soluble polymers, such as poly(ethylene oxide) and poly( $\mathrm{N}$-isopropylacrylamide) (PNIPAM), was extensively studied by fluorospectroscopy using free or chemical bounded pyrene as the fluorescence probe. However, our studies showed that pyrene is not a good probe for fluorocarbon-modified PNIPAM systems because of its poor affinity for fluorocarbon. To improve the probe's solubility in the fluorocarbon microdomain, we synthesized a pyrene derivative $\mathrm{PyCOR}_{\mathrm{f}}$ which has a fluorocarbon tail similar to the fluorocarbon monomer in the PNIPAM copolymers. ${ }^{21}$ The chemical structure of PyCOR $\mathrm{P}_{\mathrm{f}}$ is as follows:<smiles>O=C(c1ccc2ccc3cccc4ccc1c2c34)C(F)(F)C(F)(F)C(F)(F)F</smiles>

The fluorocarbon tail changes the symmetry of the pyrene structure even though the fluorescence spectrum of $\mathrm{PyCOR}_{\mathrm{f}}$ in organic solvent varies only a little. In water, PyCOR displays a special fluorescent character; namely, the monomer emission has a single peak located at $385 \mathrm{~nm}$ but no fine structure even at very dilute probe concentration $\left(2 \times 10^{-7}\right.$ $\mathrm{M})$. At a higher probe concentration $\left(1 \times 10^{-6} \mathrm{M}\right)$, a new broad band with its maximum located at $550 \mathrm{~nm}$, a typical excimer

Table 1. Static Laser Light Scattering Results of the PNIPAM Homopolymer and Fluorocarbon Modified PNIPAM Copolymers at $25^{\circ} \mathrm{C}$

\begin{tabular}{|c|c|c|c|c|c|c|c|}
\hline \multirow[b]{2}{*}{ polymer } & \multirow{2}{*}{$\begin{array}{c}\text { measured } \\
\text { fluorocarbon } \\
\text { content (mol \%) }\end{array}$} & \multirow{2}{*}{$\frac{\text { in THF }}{M_{w}}$} & \multicolumn{2}{|c|}{ in $\mathrm{H}_{2} \mathrm{O}+1$ wt \% FC-143 } & \multicolumn{2}{|c|}{ in water } & \multirow[b]{2}{*}{$\mathrm{N}_{\text {fluorocarbon }}{ }^{\mathrm{a}}$} \\
\hline & & & $\begin{array}{c}\mathrm{M}_{\mathrm{w}} \\
\left(\times 10^{4} \mathrm{~g} / \mathrm{mol}\right)\end{array}$ & $\begin{array}{c}\mathrm{A}_{2}\left(\times 10^{-3}\right. \\
\left.\mathrm{mol} \mathrm{mL} / \mathrm{g}^{2}\right)\end{array}$ & $\begin{array}{c}M_{w} \\
(g / m o l)\end{array}$ & $\begin{array}{c}\mathrm{A}_{2}\left(\times 10^{-4}\right. \\
\left.\mathrm{mol} \mathrm{mL} / \mathrm{g}^{2}\right)\end{array}$ & \\
\hline homopolymer & 0 & 6.2 & 7.4 & 2.1 & $6.4 \times 10^{4}$ & 3.8 & 0 \\
\hline Co-Fx-14-1 & 0.06 & 7.3 & & & $7.3 \times 10^{4}$ & -8.6 & 0.4 \\
\hline Co-Fx-14-2 & 0.10 & 6.0 & & & $8.6 \times 10^{4}$ & -2.5 & 0.5 \\
\hline Co-Fx-14-3 & 0.21 & 6.0 & & & $1.2 \times 10^{5}$ & -2.0 & 1.1 \\
\hline Co-Fx-14-4 & 0.41 & 6.0 & & & $1.5 \times 10^{5}$ & -1.7 & 2.2 \\
\hline Co-Fx-14-5 & 0.88 & 6.0 & 8.5 & 2.2 & $1.2 \times 10^{5}$ & -3.1 & 4.7 \\
\hline Co-Fx-13-1 & 0.08 & 8.7 & & & $8.5 \times 10^{4}$ & -1.2 & 0.6 \\
\hline Co-Fx-13-2 & 0.13 & 7.5 & & & $1.1 \times 10^{5}$ & -1.1 & 0.9 \\
\hline Co-Fx-13-3 & 0.26 & 7.5 & & & $1.2 \times 10^{5}$ & -3.0 & 1.7 \\
\hline Co-Fx-13-4 & 0.39 & 6.5 & & & $1.6 \times 10^{5}$ & -1.1 & 2.2 \\
\hline Co-Fx-13-5 & 0.82 & 7.3 & & & $1.3 \times 10^{5}$ & -4.1 & 5.3 \\
\hline Co-Fx-13-6 & 1.50 & 8.3 & & & insoluble & & 11 \\
\hline
\end{tabular}

a $\mathrm{N}_{\text {fluorocarbon }}$ is the average number of fluorocarbon monomers per copolymer chain. 


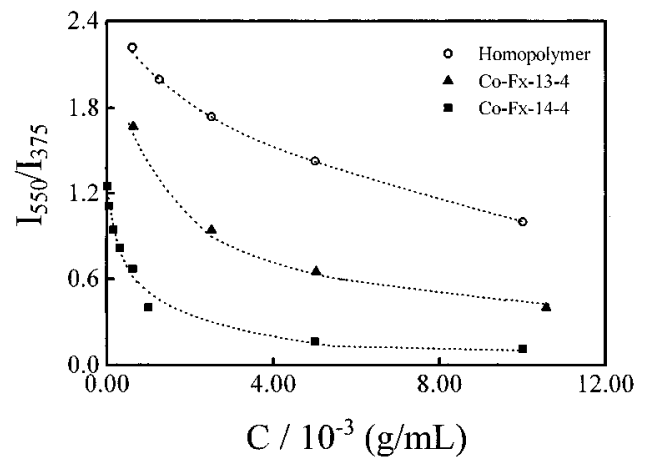

Figure 1. Polymer concentration dependence of the excimerto-monomer emission intensity ratio ${ }_{550} / \mathrm{l}_{375}$ of the fluorocarbon probe PyCOR $_{\mathrm{f}}\left(2 \times 10^{-6} \mathrm{M}\right)$, where the two copolymers contain a similar fluorocarbon content $(\sim 0.40 \mathrm{~mol} \%)$.

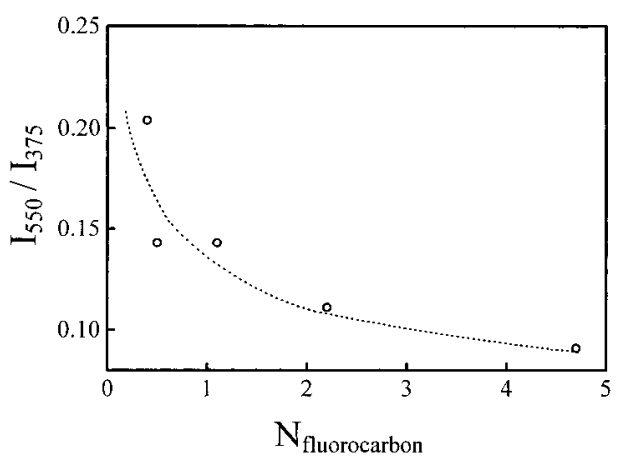

Figure 2. Fluorocarbon-content dependence of $\mathrm{I}_{550} / \mathrm{I}_{375}$ of $\mathrm{PyCOR}_{\mathrm{f}}$ in the Fx-14-co-NIPAM copolymer solution, where $\mathrm{N}_{\text {fluorocarbon }}$ is the average number of fluorocarbon monomers per copolymer chain and the copolymer concentration was 2 $\times 10^{-2} \mathrm{~g} / \mathrm{mL}$.

peak, appears due to the self-assembling of $\mathrm{PyCOR}_{\mathrm{f}}$ in water. If $\mathrm{PyCOR}_{f}$ is transferred from water to the fluorocarbon microdomain, the monomer emission gradually shows fine structures but the excimer emission decreases. The most distinguishable peak in the monomer emission is located at $375 \mathrm{~nm}$. Therefore, the intensity ratio of excimer to monomer, i.e., $I_{550} / I_{375}$, was used as an indicator to monitor the change of the environment around PyCOR . $_{\text {. }}$

\section{Results and Discussion}

Fluorescence Study. Figure 1 shows that $I_{550} / l_{375}$ decreases as the polymer concentration increases. It is known that the hydrophobic aggregation can reduce the excimer intensity and enhance the monomer emission intensity because some probe molecules diffuse from the hydrophilic water domain into the hydrophobic microdomain. Relatively, the decrease of $\mathrm{I}_{550} / \mathrm{I}_{375}$ in the homopolymer solution as the polymer concentration increases is smaller, indicating that the homopolymer aggregation of the in water is much less than the copolymer aggregation. When the copolymer concentration is higher than $2 \times 10^{-3} \mathrm{~g} / \mathrm{mL}, \mathrm{I}_{550} / \mathrm{l}_{375}$ starts to approach a constant, suggesting that most of the probe molecules are inside the aggregates. For a given polymer concentration, $\mathrm{I}_{550} / \mathrm{I}_{375}$ in the Co-Fx-14-4 solution decreases more and faster than that in the Co-Fx13-4 solution, implying that $F x-13$ and $F x-14$ have different hydrophobic effects, because $\mathrm{Fx}-14$ has an additional hydrophobic methyl group. Later, we will show that the Fx-14-co-NIPAM solution has a higher viscosity.

Figure 2 shows the $F x-14$ content dependence of the fluorescence intensity ratio $I_{550} / l_{375}$, where the copoly-

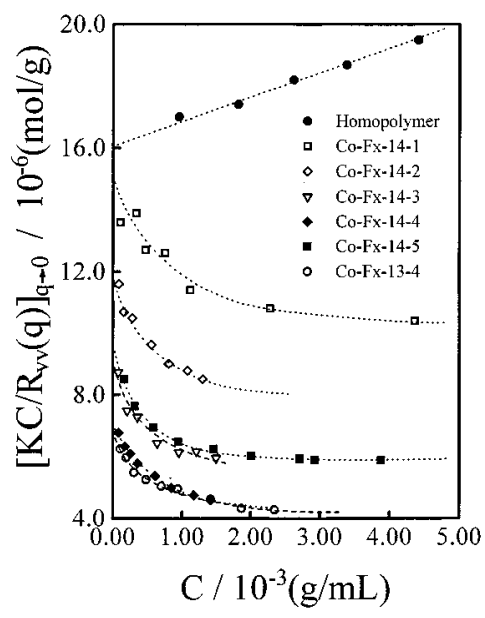

Figure 3. Polymer concentration dependence of $\left[K C / R_{w}(q)\right]_{q \rightarrow 0}$ of the PNIPAM homopolymer and copolymers in water, where $\left[K C / R_{v v}(q)\right]_{q \rightarrow 0} \propto 1 / M_{w}$.

mer concentration was kept at $2 \times 10^{-2} \mathrm{~g} / \mathrm{mL}$. The monotonic decrease of $\mathrm{I}_{550} / \mathrm{I}_{375}$ indicates that the association increases as the Fx-14 content increases. However, the fluorescence study is not able to differentiate the intrachain association from the interchain association because both of them can provide a hydrophobic microdomain to accommodate the fluorescence probes and lead to the decrease of $I_{550} / I_{375}$.

Laser Light-Scattering Study. First, we characterized each copolymer in tetrahydrofuran (THF), a good solvent, to obtain the molecular parameters, such as its molar mass and the hydrodynamic size of individual copolymer chains, which are the starting points for investigating the association of the fluorocarbon-modified poly( $\mathrm{N}$-isopropylacrylamide) in aqueous solution. All the LLS results are listed in Table 1 . The homopolymer and copolymers have a similar $M_{w}$, which is expected because the homopolymer and copolymers were prepared in an identical polymerization condition and the content of the fluorocarbon comonomer is very low. The similar molar mass also indicates that there is no association in THF even for the water-insoluble copolymer with the $\mathrm{F} x-13$ content as high as $1.5 \mathrm{~mol} \%$.

Figure 3 shows that the homopolymer solution displays an expected linear concentration dependence of $\left.\left[K C / R_{v v} q\right)\right]_{q \rightarrow 0}$, while the copolymer solutions have a negative and curvature concentration dependence. The copolymer's apparent molar mass $\left(M_{w, a p p}\right)$, which is reciprocally proportional to $\left[K C / R_{v v}(q \rightarrow 0)\right]_{q \rightarrow 0}$ on the basis of eq 1 , increases as the copolymer concentration increases, indicating the association of the copolymer chains even in the solution as dilute as $\sim 10^{-4} \mathrm{~g} / \mathrm{mL}$. The extrapolation of $\left[K C / R_{v v}(q)\right]_{c \rightarrow 0, q \rightarrow 0}$ leads to the weight average molar mass of the aggregates, also listed in Table 1, which is higher than that of individual homopolymer chains.

It should be noted that, in this case, $\mathrm{M}_{\mathrm{w}}$ was calculated from the quadratic extrapolation and the second virial coefficient $\left(A_{2}\right)$ was estimated from the initial slope. For the homopolymer, $M_{w}$ values obtained in water and THF are similar because water is al so a good solvent for PNIPAM at room temperature, but the copolymers in water have much higher molar masses than their corresponding $\mathrm{M}_{\mathrm{w}}$ values in THF, indicating the copolymer association in water even though the solution is extremely diluted. We will come back to this point later. Note that $\left[K C / R_{v v}(q)\right]_{q \rightarrow 0}$ stops decreasing 


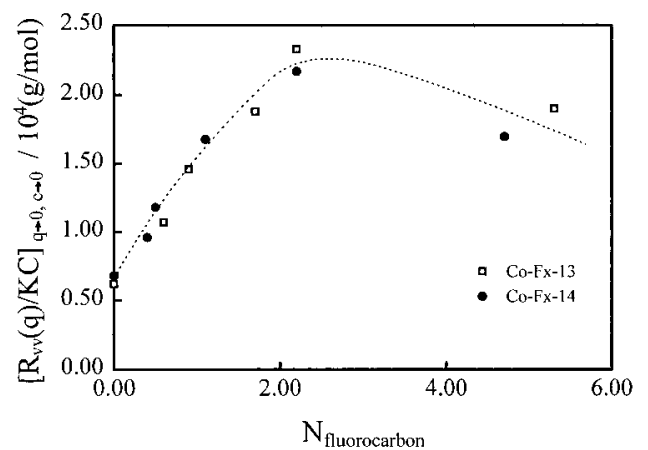

Figure 4. Fluorocarbon content dependence of $\left.\left[R_{v v} q\right) / K C\right]_{q \rightarrow 0}$ of the copolymers in water, where $\mathrm{N}_{\text {fluorocarbon }}$ is the average number of fluorocarbon monomers per copolymer chain, estimated from the average molar mass of the copolymer chains and the fluorocarbon content.

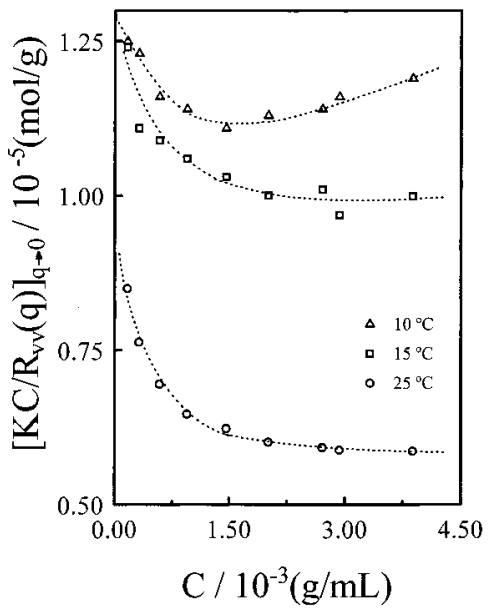

Figure 5. Polymer concentration and temperature dependence of $\left[K C / R_{v v}(q)\right]_{q \rightarrow 0}$ of the Co-F x-14-5 copolymer in water.

when the copolymer concentration is high and $\left[R_{v v^{-}}\right.$ $(q \rightarrow 0) / K C]_{q \rightarrow 0, c \rightarrow \infty}$ has the units of molar mass, suggesting the aggregates reach a certain size.

Figure 4 shows that initially, as expected, $\left[R_{v v}(q) /\right.$ $\mathrm{KC}]_{\mathrm{q} \rightarrow 0, \mathrm{C} \rightarrow \infty}$ increases as the fluorocarbon content increases, indicating the increase of the interchain association. However, the decrease of $\left[R_{v v}(q) / K C\right]_{q \rightarrow 0, c \rightarrow \infty}$ as the fluorocarbon content further increases is unexpected because the fluorescence results indicated a monotonic increase of the copolymer association as the fluorocarbon content increases. This difference can be attributed to the intrachain association occurring when a copolymer chain has a high content of fluorocarbon. It should be noted that, on one hand, the difference between the intrachain and interchain associations shown in Figure 4 cannot be distinguished in the fluorescence study but, on the other hand, the association difference between $\mathrm{Fx}-13$ and $\mathrm{Fx}-14$ shown in the fluorescence study cannot be observed in LLS.

Figure 5 shows that, for a given concentration, [KC/ $\left.R_{v v}(q)\right]_{q \rightarrow 0}$ increases (i.e., $M_{w}$ decreases) as the temperature decreases, indicating a dissociation of the aggregates as water becomes a better solvent at low temperatures. However, a complete dissociation was not reached even at the temperature as low as $10^{\circ} \mathrm{C}$ because $\mathrm{M}_{\mathrm{w}}$ is still larger than the molar mass of individual chains determined in THF. The addition of surfactant FC-143 with the same fluorocarbon structure as Fx-13 or $\mathrm{Fx}-14$ can reduce the copolymer association in water. Table 1 summarizes the results of Co-Fx-14-5 and

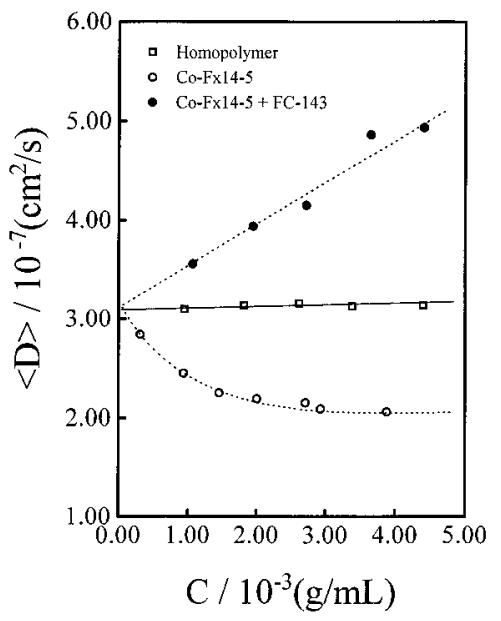

Figure 6. Polymer concentration dependence of the average translational diffusion coefficient $(\langle\mathrm{D}\rangle)$, where the surfactant (FC-143) concentration is 1 wt \%.

homopolymer in water with and without the addition of FC-143. In the case of homopolymer, $\mathrm{M}_{\mathrm{w}}$ only slightly increases after the addition of 1 wt \% FC-143, which could be attributed to a possible preferential adsorption of FC-143 on the polymer chains, while, in the case of Co-Fx-14-5, $M_{w}$ decreases, clearly indicating a dissociation of the aggregates because FC-143 acting as a surfactant can surround the fluorocarbons on the copolymer chain to prevent their association.

Figure 6 shows that, without the addition of FC-143, $\langle D\rangle$, as expected, decreases as $C$ increases because of the interchain association. On the other hand, the addition of FC-143 resulted in a linear increase of $\langle D\rangle$, typical for polymer chains in a good solvent. It is worth noting that $\langle\mathrm{D}\rangle_{\mathrm{C} \rightarrow 0}$ has a similar value in all three cases. It is understandable for the cases of the homopolymer and the copolymer in the presence of FC-143 because FC-143 has suppressed the interchain association so that the copolymer chains behave like individual homopolymer chains. As for the case of Co-Fx-14-5, it is difficult to understand why $\langle\mathrm{D}\rangle_{\mathrm{C} \rightarrow 0}$, without the addition of FC-143, is also similar to that of the homopolymer because $F$ igure 3 shows that the $\mathrm{Co}-\mathrm{F} x-14-5$ solution has a much higher $\left[K C / R_{v v}(q)\right]_{a \rightarrow 0, C \rightarrow \infty}$. This apparent contradiction can be explained in terms of the interchain and intrachain association; namely, the interchain association increases $M_{w}$ and decreases $\langle D\rangle$, but the intrachain association has no effect on $M_{w}$ and can only increase $\langle D\rangle_{C \rightarrow 0}$. The increase of the association as the fluorocarbon content increases can also be viewed in terms of the Huggins coefficient $\left(\mathrm{k}_{\mathrm{H}}\right)$ and the intrinsic viscosity.

Figure 7 shows that initially, as the fluorocarbon content increases, both $[\eta]$ and $\mathrm{K}_{\mathrm{H}}$ increase before reaching their respective maxima at $\mathrm{N}_{\text {fluorocarbon }} \sim 2$. The initial increase of $[\eta]$ confirms the interchain association observed in LLS. The decreases of $[\eta]$ and $\mathrm{K}_{\mathrm{H}}$ at higher $\mathrm{N}_{\text {fluorocarbon }}$ can be attributed to the intrachain association, similar to what we observed in Figure 4. Moreover, it has been known that the open association model can be used to describe the concentration dependence of $M_{w}$ of all the associated species in an equilibrium system. ${ }^{37-39}$ In the open association model, the starting building blocks, such as individual polymer chains or small particles, are in equilibrium with the aggregates with different sizes, i.e., $P_{1}+P_{n} \stackrel{K_{\text {eq }}}{\longrightarrow} P_{n+1}$, where $P_{n}$ is the 


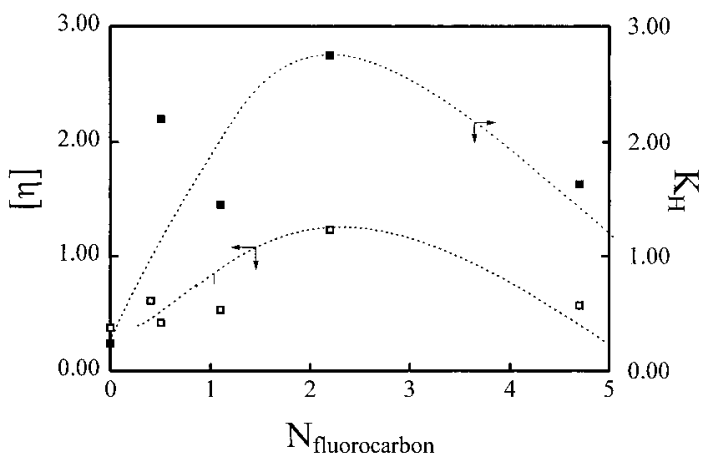

Figure 7. Fluorocarbon content dependence of the intrinsic viscosity $[\eta]$ and Huggins constant $\left(\mathrm{k}_{H}\right)$ of the Co-Fx-14 copolymer in water, where $\mathrm{N}_{\text {fluorocarbon }}$ is the average number of the fluorocarbon monomers per copolymer chain.

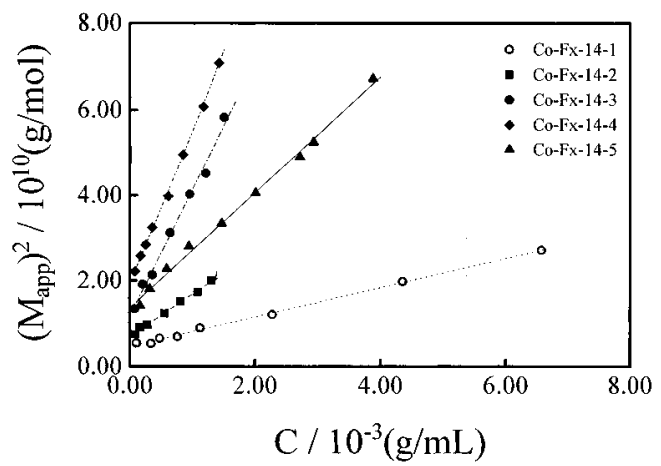

Figure 8. Polymer concentration dependence of $\mathrm{M}_{\mathrm{w}}{ }^{2}$ of the Co-Fx-14 copolymers in water, where the lines represent the least-squares fittings of $M_{w}{ }^{2}=M_{0}{ }^{2}+4 K_{\text {eq }} M_{0} C$. The fitting parameters, that is, $\mathrm{M}_{0}$ and $\mathrm{K}_{\mathrm{eq}}$, are listed in Table 2.

Table 2. Fitting Parameters Used in the Open Association Model for the Copolymers with Different Fluorocarbon Contents

\begin{tabular}{ccccc}
\hline polymer & $\mathrm{N}_{\text {fluorocarbon }}$ & $\begin{array}{c}\mathrm{K}_{\text {eq }}\left(\times 10^{4}\right. \\
\mathrm{L} / \mathrm{mol})\end{array}$ & $\begin{array}{c}\mathrm{M}_{0}\left(\times 10^{5}\right. \\
\mathrm{g} / \mathrm{mol})\end{array}$ & $\begin{array}{c}\mathrm{A}_{2}\left(\times 10^{-4}\right. \\
\left.\mathrm{mol} \mathrm{mL} / \mathrm{g}^{2}\right)\end{array}$ \\
\hline Co-Fx-14-1 & 0.4 & 1.2 & 0.69 & -3.8 \\
Co-Fx-14-2 & 0.5 & 2.9 & 0.84 & -5.0 \\
Co-Fx-14-3 & 1.1 & 6.9 & 1.1 & -6.0 \\
Co-Fx-14-4 & 2.2 & 6.5 & 1.4 & -3.0 \\
Co-Fx-14-5 & 4.7 & 2.9 & 1.2 & -2.6
\end{tabular}

aggregate consisting of $\mathrm{n}$ building blocks and the equilibrium constant $\mathrm{K}_{\text {eq }}$ is independent of $\mathrm{n}$. Assuming the building blocks are monodisperse and have a molar mass of $M_{0}$, we are able to relate the weight average molar mass $\left(\mathrm{M}_{\mathrm{w}}\right)$ of all the species in the solution to the concentration (C) by ${ }^{18} \mathrm{M}_{\mathrm{w}}{ }^{2}=\mathrm{M}_{0}{ }^{2}\left[1+4\left(\mathrm{~K}_{\mathrm{eq}} \mathrm{C} / \mathrm{M}_{0}\right)\right]=\mathrm{M}_{0}{ }^{2}$ $+4 \mathrm{~K}_{\mathrm{eq}} \mathrm{M}_{0} \mathrm{C}$, that is, $\mathrm{M}_{\mathrm{w}}{ }^{2} \propto \mathrm{C}$ in an open association.

Figure 8 shows that, for the Co-Fx-14 samples, $M_{w}{ }^{2}$ does depend on $C$ linearly, indicating that the association of the copolymer chains with different fluorocarbon contents is well-presented by the open association model. Table 2 summarizes the values of $K_{e q}$ and $M_{0}$. The decrease of $K_{\text {eq }}$ further indicates the intrachain association when $\mathrm{N}_{\text {fluorocarbon }}>2$. $\mathrm{M}_{0}$ is higher than the average molar mass of each corresponding copolymer in THF but close to the $\mathrm{M}_{\mathrm{w}}$ obtained from the extrapolation in Figure 3, indicating that the fluorocarbon copolymer chains can associate with each other even in a very dilute solution. The association in a very dilution solution is also supported by the increase of $\mathrm{I}_{550} / \mathrm{l} 375$ even in the range $(0-2) \times 10^{-5} \mathrm{~g} / \mathrm{mL}$, shown in Figure 1 . This reminds us of a previous finding that, in some cases, the association or aggregates formed in bulk may never been totally destroyed (dissolved) by dilution. ${ }^{40}$

\section{Conclusion}

A combination of laser light-scattering, viscometry, and fluorescence spectroscopy studies shows that poly(N-isopropylacrylamide) (PNIPAM) modified with a very small amount (even less than $1 \mathrm{~mol} \%$ ) of fluorocarbon monomers can association in water at room temperature. The association can be partially suppressed by the dilution of the solution, the decrease of solution temperature, and the addition of fluorocarbon surfactant. Our results indicate that, even in a solution as dilute as $\sim 2 \times 10^{-5} \mathrm{~g} / \mathrm{mL}$ and at a temperature as low as $10^{\circ} \mathrm{C}$, there still exists a small amount of interchain aggregates. Our results also indicate the existence of the intrachain association when each copolymer chain on average contains more than two fluorocarbon monomers. This finding is important in practice. For example, if the hydrophobically modified polymer is used as a thickening agent, we should reach a maximum interchain association but avoid the intrachain association. The association of the fluorocarbon-modified PNIPAM can be well-described by the open association model; namely, there is an equilibrium between individual polymer chains and all the multichain aggregates.

Acknowledgment. The financial support of this work by the National Distinguished Young I nvestigator Fund and the RGC (the Research Grants Council of the Hong Kong Government) Earmarked Grant (CUHK 305/96P, 2160063) is gratefully acknowledged. Y.-X.Z., Q.F., M.F., and M.L. would like to thank the National Natural Science Foundation of China (NNSFC) for financial support.

\section{References and Notes}

(1) Franks, F. Water: A comprehensiveTreatise; Franks, F., Ed.; Plenum: New York, 1975; Vol. 4.

(2) Ben-Maim, A. Hydrophobic interaction; Plenum: New York, 1980.

(3) Tanford, C. The hydrophobic Effect: Formation of micelles and biological membranes; Wiley-Interscience: New York, 1973.

(4) Evani, S.; Rose, G. D. Polym. Mater. Eng. Prepr. 1987, 57 , 477.

(5) Bock, J .; Siano, D. B.; Schulz, D. N.; Turner, S. R.; Valint, P. L.; Pace, S. J. Polym. Mater. Sci. Eng. 1986, 55, 355.

(6) Valint, P. L.; Bock, J. Polym. Mater. Sci. Eng. 1986, 55, 361. Valint, P. L.; Bock. Macromol ecules 1988, 21, 175.

(7) Glass, J. E. Polymers in Aqueous Media; Advances in Chemistry Series No. 223; American Chemical Society: Washington, DC, 1989.

(8) Shalaby, S. W.; McCormick, C. L.; Butler, G. B. Water Soluble Polymers; ACS Symposium Series \#467; American Chemical Society: Washington, DC, p 1199.

(9) Dubin, P.; Bock, J .; Davis, R.; Shulz, D. N.; Thies, C. Macromol ecular Complex in Chemistry and Biology; SpringerVerlag: New York, 1994.

(10) Schulz, D. N.; Kaladas, I I .; Maurer, J I .; Bock, J .; Pace, S. J .; Schulz, W. W. Polymer 1987, 28, 2110.

(11) McCormick, C. L.; Hoyle, C. E.; Clark, D. Proc. Polym. Mater Sci. Eng. 1987, 57, 643.

(12) Flynn, C. E.; Goodwin, J . W. D. Proc. Polym. Mater. Sci. Eng. 1989, 61, 522

(13) Valint, P. L., J r.; Bock, J .; Ogletree, J .; Lushma, S.; Pace, S. J. Polym. Prepr. 1990, 31 (2), 67.

(14) Landoll, L. M. J . Polym. Sci. Chem. 1982, 20, 443.

(15) Sau, A. C. Polym. Mater. Sci. Eng. Prepr. 1987, 57, 497

(16) Zhang, Y. X.; Da, A. H.; Butler, G. B.; Hogen-Esch, T. E. J Polym. Sci., Polym. Chem. Ed. 1992, 30, 1383.

(17) Schild, H. G. Prog. Polym. Sci. 1992, 17, 163.

(18) Ringsdorf, H.; Venzmer, J .; Winnik, F. Macromol ecules 1991 24, 1678. 
(19) Schild, H. G.; Tirrell. D. Langmuir 1991, 7, 1317.

(20) Winnik, F. Macromolecules 1987, 20, 2754. Winnik, F. Macromolecules 1989, 22, 734.

(21) Li, M.; J iang, M.; Zhang, Y.-X.; Fang, Q. Macromolecules 1997, 30, 470.

(22) Wang, Y.; Winnik, M. Langmuir 1990, 6, 1437.

(23) Yekta, A.; Xu, B.; Buhamel, J .; Adiwidjaja, H.; Winnik, M. Macromol ecules 1995, 28, 956.

(24) Ringsdorf, H.; Venzmer, J .; Winnik, F. Macromol ecules 1991, 24, 1678.

(25) Rao, B.; Vemura, Y.; Dyke, L.; MacDonald, P. Macromolecules 1995, 28, 531.

(26) Uemura, Y.; McNulty, J .; MacDonald, P. Macromolecules 1995, 28, 4150.

(27) Person, K.; Adramsen, S.; Stilbs, P.; Hansen, F.; Walderhaug, H. Colloid Polym. Sci. 1992, 270, 465.

(28) Seery, T. A. P.; Yassini, M.; Hogen-Esch, T. E.; Amis, E. J . Macromolecules 1992, 25, 4784.

(29) Zhang, Y.; Wu, C.; Fang, Q.; Zhang, Y.-X. Macromolecules 1996, 29, 2494.
(30) Wu, C.; Xia, K.-Q. Rev. Sci. Instrum. 1994, 65, 587.

(31) Zimm, B. H. J . Chem. Phys. 1948, 16, 1099.

(32) Berne, B. J .; Pecora, R. Dynamic Light Scattering; Wiley: New York, 1976.

(33) Chu, B. Laser Light Scattering; Academic press: New York, 1974.

(34) Provencher, S. W. Makromol. Chem. 1979, 180, 201.

(35) Stockmayer, W. H.; Schmidt, M. Pure Appl. Chem. 1982, 54, 407.

(36) Stockmayer, W. H.; Schmidt, M. Macromolecules 1984, 17, 509.

(37) Elias, H. G. In Light Scattering from Polymer Solution; Huglin, M. B., Ed.; Academic Press: London, 1972; Chapter 9.

(38) Pedly, A. M.; Higgins, J. S.; Peiffer, D. G.; Burchard, W. Macromolecules 1990, 23, 1434

(39) Yong, A. M.; Higgins, J. S.; Peiffer, D. G.; Rennie, A. R. Polymer 1995, $36(4), 691$.

(40) Wu, C.; Woo, K.; J iang, M. Macromolecules 1996, 29, 5361. MA9714171 